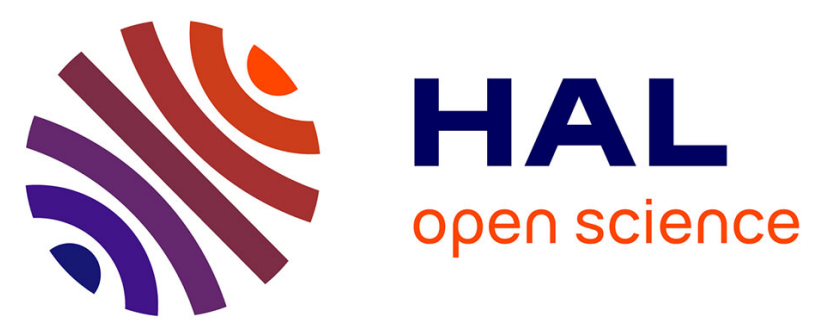

\title{
Antimicrobial and anthelmintic activities of the ethanolic extract, fractions and isolated compounds from Manilkara zapota L. P. Royen (Sapotaceae)
}

Layany Carolyny Mourão Mulvaney, Francisco Humberto Xavier-Júnior, Alice M S Rodrigues, Didier Stien, Silmara Marques Allegretti, Vera Lúcia Garcia

\section{To cite this version:}

Layany Carolyny Mourão Mulvaney, Francisco Humberto Xavier-Júnior, Alice M S Rodrigues, Didier Stien, Silmara Marques Allegretti, et al.. Antimicrobial and anthelmintic activities of the ethanolic extract, fractions and isolated compounds from Manilkara zapota L. P. Royen (Sapotaceae). Journal of Pharmacy and Pharmacology, 2021, 73, pp.377-387. 10.1093/jpp/rgaa030 . hal-03137153

\section{HAL Id: hal-03137153 \\ https://hal.science/hal-03137153}

Submitted on 18 Feb 2021

HAL is a multi-disciplinary open access archive for the deposit and dissemination of scientific research documents, whether they are published or not. The documents may come from teaching and research institutions in France or abroad, or from public or private research centers.
L'archive ouverte pluridisciplinaire HAL, est destinée au dépôt et à la diffusion de documents scientifiques de niveau recherche, publiés ou non, émanant des établissements d'enseignement et de recherche français ou étrangers, des laboratoires publics ou privés. 
1 Antimicrobial and anthelmintic activities of the ethanolic extract, fractions, and isolated compounds from Manilkara zapota L. P. Royen (Sapotaceae)

3 Layany Carolyny Mourão Mulvaney ${ }^{\text {a,b }}$, Francisco Humberto Xavier-Júnior ${ }^{c}$, Alice

4 M.S. Rodrigues ${ }^{\mathrm{d}}$, Didier Stien ${ }^{\text {b,d }}$, Silmara Marques Allegretti ${ }^{\mathrm{e}}$, Vera Lúcia Garcia ${ }^{\mathrm{a}^{*}}$

5 a. Chemical, Biological and Agricultural Pluridisciplinary Research Center, University 6 of Campinas, Campinas, São Paulo, Brazil

7 b. CNRS- Institut de Chimie des Substances Naturelles, Gif-sur-Yvette, France

8 c. Programa de Pós-Graduação em Biotecnologia, Universidade Potiguar (UnP),

9 Campus Salgado Filho, 59075-000, Natal, RN, Brazil.

10 d. Sorbonne Universités, UPMC Univ Paris 06, CNRS, Laboratoire de Biodiversité et 11 Biotechnologies Microbiennes (LBBM), Observatoire Océanologique, Banyuls-sur12 mer, France

13 e. Department of Animal Biology, Institute of Biology, University of Campinas, 14 Campinas, São Paulo, Brazil

\section{5 *Corresponding author:}

16 Vera Lúcia Garcia

17 Chemical, Biological and Agricultural Pluridisciplinary Research Center (CPQBA) Av. Alexandre Cazelatto, 999, CEP: 13148-218 Paulínia, SP, Brazil 
Objectives: To evaluate the antibacterial, antifungal, and anthelmintic activities of the ethanolic extract (EEMz), fractions (LPFMz and HPFMz), and compounds isolated from the leaves of Manilkara zapota L. P. Royen.

Methods: Extract and fractions were produced by turbolization. LPFMz fraction was analyzed by GC-MS. The isolated compounds from HPFMz were purified by flash and preparative chromatographic methods, and chemically characterized by UPLCESITOFMS, optical rotation, and one- and two-dimensional ${ }^{1} \mathrm{H}$ and ${ }^{13} \mathrm{C} \mathrm{NMR}$ techniques. Anthelmintic against Strongyloides venezuelensis and antimicrobial activities against Candida albicans, Trichophyton rubrum and Staphylococcus aureus were evaluated.

Key findings: EEMz showed mainly phenolic compounds and pentacyclic triterpenes from $\Delta 12$-oleane/ $\Delta 12$-ursane series. Chlorogenic acid, myricetin-3-O- $\beta$-Dglucopyranoside, mearnsitrin, germanicol, and germanicol acetate were reported to $M$. zapota leaves for the first time in this work. EEMz, HPFMz, LPFMz showed significative activity against $C$. albicans $(16 \mu \mathrm{g} / \mathrm{mL})$, while isolated flavonoids were active against $S$. aureus $(<32 \mu \mathrm{g} / \mathrm{mL})$. EEMz, phenolic-rich compounds $\left(\mathrm{F}_{2}\right)$, and chlorogenic acid were potentially active against $S$. venezuelensis at $24 \mathrm{~h}$.

Conclusions: $M$. zapota and its bioactive compound can be eligible such as a potential phytomedicine for the treatment of microbial and strongyloidiasis drug-resistant

41 infections.

KEY-WORDS: Traditional medicine Meso- and Southern America; phytochemistry; anthelmintic; antimicrobial; chromatography. 
- $\quad$ Phenolic and pentacyclic triterpenes from $\Delta 12$-oleane/ $\Delta 12$-ursane were detected

- Chlorogenic acid, myricetin-3-O- $\beta$-D-glucopyranoside, mearnsitrin were

48 identified

49 - The pentacyclic triterpenes presented promising antimicrobial activity

50 - Ethanolic extract and phenolic fractions showed high antifungal activity

51 - Ethanolic and phenolic fractions, and chlorogenic acid exhibited anthelmintic 52 action

\section{Abbreviation List}

54 CAD: Charged Aerosol Detector

55 Compound 1: chlorogenic acid

56 Compound 2: myricetin-3-O- $\beta$-D-glucopyranoside

57 Compound 3: myricitrin

58 Compound 4: mearnsitrin

59 Compound 5: germanicol

60 Compound 6: $\beta$ - amyrin

61 Compound 7: $\alpha$-amyrin

62 Compound 8: germanicol acetate

63 COSY: Correlation Spectroscopy

64 EEMz: dry ethanolic extract

65 ESI: Electrospray interface

66 F: fraction obtained from High polarity insoluble fraction

67 HMBC: Heteronuclear Multiple Bond Correlation

68 HPFMz: High polarity insoluble fraction

69 HRMS: High Resolution Mass Spectroscopy

70 HSQC: Heteronuclear Single Quantum Coherence

71 LPFMz: lower polarity fraction

72 Mz: Manilkara zapota

73 PVP: polyvinylpyrrolydone

74 TOF: Time-of-flight 


\section{INTRODUCTION}

Infectious diseases caused by bacteria, viruses, fungi, and parasites are the greatest cause of death, disability, and social and economic difficulties for millions of people worldwide $^{[1]}$. This problem is especially high in developing countries, due to poor availability of drugs and the emergence of widespread drug resistance ${ }^{[2]}$. Infections caused by microorganisms such as Staphylococcus aureus can promote disorders in the skin and mucosa, toxic shock syndrome, endocarditis, osteomyelitis, and infections of the urinary and intestinal tracts. ${ }^{[3]}$. Additionally, dermatophyte fungi are also able to invade the keratinized tissues of animals and humans ${ }^{[4]}$. Among them, Trichophyton rubrum is most widespread, representing $80 \%$ of clinical isolates ${ }^{[5]}$. Candida albicans is another important opportunistic pathogenic fungus that causes candidiasis responsible for a variety of conditions in humans, ranging from superficial cutaneous lesions to generalized infection ${ }^{[6]}$.

In the same way, helminthiases caused by intestinal nematodes and transmitted via the soil are the most common and persistent neglected parasitic infections, especially in developing countries. Strongyloides stercoralis is the main neglected geohelminths responsible to infect $30-100$ million people in the world ${ }^{[7,8]}$. The autoinfection ability of S. stercoralis leads to syndromes of persistent infection that can result in chronic illness with various clinical manifestations. In immunocompromised patients, the uncontrolled multiplication of the parasite (hyperinfection) and the potentially fatal distribution of larvae in various organs represents a major concern in terms of public health ${ }^{[8 ; 9]}$.

Therefore, the discovery of new compounds with chemical structures and mechanisms of action different from those current antimicrobial and anthelmintic drugs are urgently need. This fact is due to the increased incidence of new and reemerging infectious diseases, the ineffectiveness of treatments using broad-spectrum anthelmintics, and especially the increasing inefficacy of the drugs employed in the current therapy against pathogenic microorganisms and intestinal parasites ${ }^{[10 ; 11]}$.

Manilkara zapota (L.) (Synonyms: M. zapotilla, M. achras, Mimusops manilkara, Achras zapota), commonly known as sapoti, is a member of the Sapotaceae family and it represents a potential natural resource to treat infectious process ${ }^{[12]}$. In folk medicine, the leaves are used to treat coughs, colds, and diarrhea, the crushed seeds are used as a 
108 diuretic and febrifuge, and the husks have astringent and febrifuge activities ${ }^{[13]}$. In the

109 literature, M. zapota has been reported to exhibit antioxidant properties ${ }^{[14 ; 15]}$, as well as 110 analgesic ${ }^{[16]}$, antimicrobial ${ }^{[17 ; ~ 18]}$, antihyperglycemic, and hypocholesterolemic 111 activities ${ }^{[19 ; 20]}$, due the presence of phenolic acids, flavonoids, tannins (mainly in the 112 immature fruit), triterpenes, and saponins (mainly in seeds) compounds ${ }^{[19 ; 21-23]}$. Despite 113 these important properties, the bioguided phytochemical study of the compounds from 114 the M. zapota leaves has not yet been developed. In this sense, the goal of this work was 115 to characterize the phytochemistry of the ethanolic extract, fractions, and isolated 116 compounds from the Manilkara zapota L. P. Royen leaves and to evaluate their 117 antimicrobial action and, for the first time, their anthelmintic activity.

\section{MATERIALS AND METHODS}

\subsection{Materials}

121 Leaves of Manilkara zapota (Mz) were collected from the orchard of the Multidisciplinary Center for Chemical, Biological, and Agricultural Research (CPQBA) in Campinas, São Paulo State, Brazil (22 47' 52" S, $47^{\circ} 6^{\prime} 4^{\prime \prime}$ W). A sample was deposited in the Herbarium of the Institute of Biology of the State University of Campinas, under registration no. UEC 186541. Ivermectin and chlorogenic acid (95\%) were puchased from Sigma-Aldrich (St. Louis, MO, USA) and used as a control drug and an analytical standard, respectively, in the anthelmintic activity assays. Polyvinylpyrrolidone (PVP-K30) was obtained from Synth (São Paulo, Brazil). Oxacillin, itraconazole, and fluconazole from Molekula (Dorset, UK) were used as control drugs in the antimicrobial activity assays. All solvents employed in the study were HPLC or UPLC grade.

\subsection{Bioactive compounds of the $M$. zapota}

\subsubsection{Ethanolic extract of the $M$. zapota}

The ethanolic extract was produced by turbolization. $900 \mathrm{~g}$ of the triturated and dried leaves of M. zapota were dispersed in $3 \mathrm{~L}$ of ethanol under constant stirring at 16,000 rpm for 10 min using a mechanical disperser (Ultra Turrax T50, IKA Works Inc., 
non-soluble particles. Afterthat, the residue was re-extracted with $3 \mathrm{~L}$ of ethanol and filtrated. The extracts were combined and the solvent was evaporated under vacuum until complete dryness, resulting in the dry ethanolic extract (EEMz, $96.47 \mathrm{~g}$ ).

\subsubsection{Fractions of the $M$. zapota}

$30 \mathrm{~g}$ of the EEMz was suspended in $300 \mathrm{~mL}$ of hexane/ethyl acetate mixture (1:1) and extracted in the Ultra Turrax system for $5 \mathrm{~min}$ at 16,000 rpm. Lower polarity fraction (LPFMz) and the high polarity insoluble fraction (HPFMz) were obtained. These fractions were gently separated by centrifugation at 5,000 $\mathrm{g}$ for $15 \mathrm{~min}$ and posteriorly dried under vacuum in order to produce $16.25 \mathrm{~g}$ and $11.44 \mathrm{~g}$ of LPFMz and HPFMz, respectively.

\subsubsection{Isolation of the $M$. zapota compounds}

$1.5 \mathrm{~g}$ of the HPFMz was purified by flash chromatography using a Combi Flash ${ }^{\circledR} \mathrm{Rf}^{+}$ Teledyne ISCO system (Lincoln, NE, EUA) equipped with a UV detector and C18 column (86 g). A flow rate of $60 \mathrm{~mL} / \mathrm{min}$ and $\mathrm{H}_{2} \mathrm{O} / \mathrm{CH}_{3} \mathrm{CN}$ gradient of: 80/20 for $6 \mathrm{~min}$ $\left(F_{1}\right), 80 / 20$ to $70 / 30$ in $1 \mathrm{~s}, 70 / 30$ for $6 \mathrm{~min}\left(F_{2}\right), 70 / 30$ to $60 / 40$ in $1 \mathrm{~s}, 60 / 40$ for 6 min $\left(\mathrm{F}_{3}\right), 60 / 40$ to $50 / 50$ in $1 \mathrm{~s}, 50 / 50$ for $6 \mathrm{~min}\left(\mathrm{~F}_{4}\right), 50 / 50$ to $0 / 100$ in $1 \mathrm{~s}$, and $0 / 100$ for 6 $\min \left(\mathrm{F}_{5}\right)$, was used to obtain five diferents fractions. Subsequently, the fractions $\mathrm{F}_{2}$ and $\mathrm{F}_{3}$ were combined and purified by preparative HPLC system (Gilson, Middleton, WI, USA) equipped with a model 322 pump, a GX-271 fraction collector, a DAD 171 diode array detector, and a prepELSII electrospray accessory. A Phenomenex Luna preparative C18 column $(21.2 \times 250 \mathrm{~mm}, 5 \mu \mathrm{m})$ (Torrance, CA, USA) was employed at a flow rate of $17 \mathrm{~mL} / \mathrm{min}$. The gradient apllied was $\mathrm{H}_{2} \mathrm{O} / \mathrm{CH}_{3} \mathrm{CN}(98 / 2$ to $77 / 23$ in 5 min, 77/23 to 55/45 in $15 \mathrm{~min}, 55 / 45$ to 0/100 in $5 \mathrm{~min}$ ). Four compounds 1 (3.5 mg, Rt $2.14 \mathrm{~min}) ; 2$ (0.7 mg, Rt 3.51 min); 3 (13.8 mg, Rt $4.14 \mathrm{~min}) ; 4$ (4.6 mg, Rt $5.26 \mathrm{~min}$ ) were isolated and chracterized.

\subsection{Identification of the components by chromatography analyses}

\subsubsection{Thin layer chromatography}

Thin layer chromatography analyses were performed using aluminum plates coated with silica gel $60 \mathrm{~F}_{254}$ (Merck, Darmstadt, Germany). The lower polarity compounds were 
elueted with hexane: ethyl acetate (70:30) and ethanolic anisaldehyde was used as stain.

For the high polarity compounds, the mobile phase was ethyl acetate: formic acid: glacial acetic acid: water $(52: 11: 11: 26)$ and a solution of diphenylboryloxyethylamine and polyethyleneglycol (NP/PEG) was used as the developer. UV detection was performed at 254 and $366 \mathrm{~nm}$.

\subsubsection{Gas chromatography-mass spectrometry (GC-MS)}

A gas chromatograph (Agilent, model 6890, Santa Clara, CA, USA) coupled to an Agilent 5975 mass spectrometer was used to identify compounds present in LPFMz. The analyses were performed using an HP-5MS capillary column $(30 \mathrm{~m} \times 0.25 \mathrm{~mm}$, $0.25 \mu \mathrm{m})(\mathrm{J} \& \mathrm{~W}$ Scientific, Santa Clara, CA, USA). The column temperature was increased from $110{ }^{\circ} \mathrm{C}$ to $280{ }^{\circ} \mathrm{C}$ during $26 \mathrm{~min}$, using a heating rate of $5{ }^{\circ} \mathrm{C} / \mathrm{min}$. The injector and detector were maintained at $250{ }^{\circ} \mathrm{C}$ and $300{ }^{\circ} \mathrm{C}$, respectively. The carrier gas was helium at a flow rate of $1 \mathrm{~mL} / \mathrm{min}$. The mass spectra were obtained using an ionization energy of $70 \mathrm{eV}$ and $\mathrm{m} / z$ from 40 to 600 a.m.u.. Injection of $1 \mu \mathrm{L}$ of sample was made in split mode (1:30). The compounds were identified by comparison of the fragmentation patterns with data in the NIST 11 spectral library and data reported in the literature.

\subsubsection{HPLC analyses}

The analytical profiles were obtained with a Dionex UltiMate 3000 system equipped with dual PDA and Corona CAD detectors (Thermo Fisher Scientific, Waltham, MA, USA). A Cortecs C18 column was used (4.6 × $150 \mathrm{~mm}, 2.7 \mu \mathrm{m})$ (Waters, Milford, MA, USA). Elution was performed using a linear gradient of $\mathrm{H}_{2} \mathrm{O}$ mixed with an increasing proportion of $\mathrm{CH}_{3} \mathrm{CN}$. The flow rate was of $1.6 \mathrm{~mL} / \mathrm{min}$. The data were obtained with Chromeleon ${ }^{\mathrm{TM}}$ Chromatography Data System (CDS) Software.

\subsection{Structural elucidation of the HPFMz}

\subsubsection{Optical rotation}

200 The optical rotation was measured in methanol (MeOH) using an Anton Paar MCP 300 polarimeter (Graz, Austria) equipped with a $350 \mu \mathrm{L}$ cell with a length of $100 \mathrm{~mm}$. 
203

204

205

206

207

208

209

210

211

212

213

214

215

216

217

218

219

220

221

222

223

224

225

226

227

228

229

230

231

232

233

234

\subsection{2. ${ }^{1} \mathrm{H}$ and ${ }^{13} \mathrm{C}$ NMR and $2 \mathrm{D}-\mathrm{NMR}$ spectra}

NMR analyses were performed in a Bruker (Billerica, MA, USA) $500 \mathrm{MHz}$ spectrometer equipped with a $1 \mathrm{~mm}$ inverse detection probe. The samples were dissolved in deuterated methanol $\left(\mathrm{CD}_{3} \mathrm{OD}\right)$ in $5 \mathrm{~mm}$ tubes. The chemical shifts $(\delta$, in ppm) were reported based on the signal for tetramethylsilane (TMS).

\subsubsection{High resolution mass analyses}

High resolution mass measurements (ESITOFMS) were performed in Acquity UPLC system (Waters, Milford, MA, USA) coupled to a Waters Micromass LCT Premier mass spectrometer equipped with an electrospray interface (ESI) and a time-of-flight (TOF) detector.

Compound 1: Yellow powder; $\mathrm{R}_{\mathrm{f}} \sim 0.45$ with blue fluorescence at $366 \mathrm{~nm}$. $\lambda_{\max }: 327$ $\mathrm{nm} ;{ }^{1} \mathrm{H}$ NMR $\left(\mathrm{CD}_{3} \mathrm{OD}\right) 7.56(1 \mathrm{H}, \mathrm{d}, J=15.8 \mathrm{~Hz}, \mathrm{H}-7), 7.05(1 \mathrm{H}, \mathrm{d}, J=1.8 \mathrm{~Hz}, \mathrm{H}-2$ '), $6.96(1 \mathrm{H}, \mathrm{dd}, J=7.9,1.8 \mathrm{~Hz}, \mathrm{H}-6$ ') $6.77(1 \mathrm{H}, \mathrm{d}, J=7.9 \mathrm{~Hz}, \mathrm{H}-5$ ') $6.37(1 \mathrm{H}, \mathrm{d}, J=$ $15.8 \mathrm{~Hz}, \mathrm{H}-8$ '), 4.20 (1H, m), 3.85 (1H, m), 2.05 (1H, br.s), 1.93 (br.s); HRESITOFMS $[\mathrm{M}-\mathrm{H}]^{-}$calculated for $\mathrm{C}_{16} \mathrm{H}_{17} \mathrm{O}_{9}, \mathrm{~m} / z$ 353.0872.

Compound 2: Yellow powder; $\mathrm{R}_{\mathrm{f}} \sim 0.65$ with orange fluorescence at $366 \mathrm{~nm}$. $[\alpha]_{\mathrm{D}}^{25}$ :$12^{\circ}\left(c 0.1 \mathrm{~g} / 100 \mathrm{~mL}, \mathrm{CH}_{2} \mathrm{OH}\right) ; \lambda_{\max }: 261,356 \mathrm{~nm} ;{ }^{1} \mathrm{H} \mathrm{NMR}\left(\mathrm{CD}_{3} \mathrm{OD}\right): \delta 3.23(1 \mathrm{H}$, ddd, $J=9.5,5.2,2.4$ H-5”), 3.38 (1H, dd, $J=9.5,8.8 \mathrm{~Hz}, \mathrm{H}-3$ ”), 3.42 (1H, t, $J=8.8 \mathrm{~Hz}, \mathrm{H}-$ 4”), 3.51 (1H, dd, $J=8.8,7.9 \mathrm{~Hz}, \mathrm{H}-2 ”), 3.62$ (1H, d, $J=11.9,5.2 \mathrm{~Hz}, \mathrm{H}-6 \beta ”), 3.73$ (1H, dd, $\left.J=11.9,2.4 \mathrm{~Hz}, \mathrm{H}-6 \alpha^{\prime \prime}\right), 5.26$ (1H, d, $J=7.9 \mathrm{~Hz}, \mathrm{H}-1$ ”), 6.20 (1H, d, $J=2.1$ $\mathrm{Hz}, \mathrm{H}-6), 6.38(1 \mathrm{H}, \mathrm{d}, J=2.1 \mathrm{~Hz}), 7.30(2 \mathrm{H}, \mathrm{s})$; HRESITOFMS [M - H] $]^{-}, m / z$ 479.0820 (calculated for $\mathrm{C}_{21} \mathrm{H}_{19} \mathrm{O}_{13}, m / z, 479.0826$ ) and $[\mathrm{M}+\mathrm{H}]^{+}, m / z 481.0986$ (calculated for $\mathrm{C}_{21} \mathrm{H}_{21} \mathrm{O}_{13}, \mathrm{~m} / z$ 481.0982).

Compound 3: Yellow powder; $\mathrm{R}_{\mathrm{f}} \sim 0.8$ with orange fluorescence at $366 \mathrm{~nm}$. $\left[\alpha{ }^{25}{ }_{\mathrm{D}}\right.$ : $61^{\circ}\left(c 0.1 \mathrm{~g} / 100 \mathrm{~mL}, \mathrm{CH}_{2} \mathrm{OH}\right), \lambda_{\max }: 261,350 \mathrm{~nm} ;{ }^{1} \mathrm{H} \mathrm{NMR}\left(\mathrm{CD}_{3} \mathrm{OD}\right): \delta 0.96(3 \mathrm{H}, \mathrm{d}, \mathrm{J}$ = 6.1, H-6"), 3.52 (1H, dd, $J=9.2,6.1, \mathrm{H}-5 ”), 3.34$ (1H, t, $J=9.2 \mathrm{~Hz}, \mathrm{H}-4 ”), 3.79$ (1H, dd, $J=9.2,3.0 \mathrm{~Hz}, \mathrm{H}-3$ ”), 4.22 (1H, dd, $J=3.0,1.2 \mathrm{~Hz}, \mathrm{H}-2$ "), 5.32 (1H, d, $J=1.2 \mathrm{~Hz}$, H-1”), 6.20 (1H, d, $J=1.8$ Hz, H-6), 6.36 (1H, d, $J=1.8$ Hz), 6.95 (2H, s, H-2', H-6'); ${ }^{13} \mathrm{C}$ NMR (CD $\left.{ }_{3} \mathrm{OD}\right): 179.58$ (C-4), 166.55 (C-7), 163.15 (C-5), 159.34 (C-2), 158.55 (C-9), 146.84 (C-3', C-5'), 137.91 (C-4'), 136.25 (C-3), 121.91 (C-1'), 109.55 (C2',6’), 105.67 (C-10), 103.60 (C-1”), 100.00 (C-6), 94.83 (C-8), 73.34 (C-4”), 72.11 (C- 

(calculated for $\mathrm{C}_{21} \mathrm{H}_{19} \mathrm{O}_{12}, m / z$ 463.0877) and $[\mathrm{M}+\mathrm{H}]^{+}, m / z 465.1032$ (calculated for $\left.\mathrm{C}_{21} \mathrm{H}_{21} \mathrm{O}_{12}, m / z, 465.1033\right)$.

238 Compound 4: Yellow powder; $\mathrm{R}_{\mathrm{f}} \sim 0.85$ with yellow fluorescence at $366 \mathrm{~nm}\left[\alpha{ }^{25}{ }_{\mathrm{D}}\right.$ :$23958^{\circ}\left(c 0.1 \mathrm{~g} / 100 \mathrm{~mL}, \mathrm{CH}_{2} \mathrm{OH}\right), \lambda_{\max }: 263,337 \mathrm{~nm} .{ }^{1} \mathrm{H}$ NMR $\left(\mathrm{CD}_{3} \mathrm{OD}\right): \delta 0.95(3 \mathrm{H}, \mathrm{d}, J$ $240=5.7, \mathrm{H}-6 ”), 3.32$ (m, H5”), 3.33 (m, H4”), 3.75 (1H, dd, J = 9.2, 3.5 H-3”), 3.88 (3H, s, 2414 ' $\left.-\mathrm{OCH}_{3}\right), 4.22(1 \mathrm{H}, \mathrm{dd}, J=3.5,1.9 \mathrm{~Hz}, \mathrm{H}-2$ "’), 5.30 (1H, d, $J=1.9 \mathrm{~Hz}, \mathrm{H}-1$ '”), 6.13 $242(1 \mathrm{H}, \mathrm{d}, J=2.2 \mathrm{~Hz}, \mathrm{H}-6), 6.27(1 \mathrm{H}, \mathrm{d}, J=2.2 \mathrm{~Hz}), 6.87\left(2 \mathrm{H}, \mathrm{s}, \mathrm{H}-2\right.$ ', H-6'); ${ }^{13} \mathrm{C}$ NMR 243 (CD $\left.{ }_{3} \mathrm{OD}\right)$ : 168.27 (C-7), 158.77 (C-2), 152.28 (C-3', C-5'), 139.28 (C-4'), 127.42 (C1'), 109.91 (C-2', C-6'), 103.63 (C-1”), 100.65 (C-6), 95.85 (C-8), 73.40 (C-5”), 72.27 (C-4”), 72.15 (C-3”), 72.05 (C-2”), 61.04 (4'-OCH 3 ), 17.86 (C-6”). HRESITOFMS [M $-\mathrm{H}]^{-}, m / z 477.1039$ (calculated for $\mathrm{C}_{22} \mathrm{H}_{21} \mathrm{O}_{12}, m / z$ 477.1033) and $[\mathrm{M}+\mathrm{H}]^{+}, m / z$ 479.1180 (calculated for $\mathrm{C}_{22} \mathrm{H}_{23} \mathrm{O}_{12}, \mathrm{~m} / \mathrm{z} 479.1190$ ).

\subsection{Antimicrobial activity}

The antimicrobial activities of the EEMz, HPFMz, LPFMz, and isolated flavonoids 2, 3, and 4 were analyzed against S. aureus (ATCC 29213), C. albicans (ATCC 10231), and T. rubrum (SNB-TR1). The broth microdilution technique was used to determine the minimal inhibitory concentration (MIC) according to the guidelines of the Clinical and Laboratory Standards Institute (CLSI) ${ }^{[24 ; 25]}$. Previously, the samples were solubilized with dimethyl-sulfoxide (DMSO). Then, the solutions were placed in 96-well microplates, diluted in a growth medium. Lastly, the pathogen suspension was added, resulting in concentrations ranging from 512 to $1 \mu \mathrm{g} / \mathrm{mL}$. The microplates were for incubated at $37{ }^{\circ} \mathrm{C}$ for $24 \mathrm{~h}$ (bacteria), $48 \mathrm{~h}$ (yeast), and 5 days (dermatophyte). Oxacillin (16-0.03 $\mu \mathrm{g} / \mathrm{mL})$ was used as a reference antibiotic, while itraconazole (16$0.03 \mu \mathrm{g} / \mathrm{mL})$ and fluconazole $(64-0.125 \mu \mathrm{g} / \mathrm{mL})$ were employed as positive controls for antifungal activity. The concentrations of DMSO were less than $0.5 \%$, thus not toxic for the micro-organisms. MIC was determined as the lowest concentration that prevented microbial growth.

\subsection{Anthelmintic activity}


266 All the experiments employing animals were approved by the Ethics Committee for the

267 Use of Animals (CEUA/UNICAMP, protocol no. 4089-1/2015) and complied with the ethical principles for animal experimentation adopted by CEUA, State University of Campinas. Adults (triploid parthenogenetic females) of Strongyloides venezuelensis were isolated from the rodent Bolomys lasiuris and maintained in Rattus norvegicus. Infective larvae (L3) of S. venezuelensis were obtained by coproculture. The cultures were collected, concentrated and mantained at $28^{\circ} \mathrm{C}$ for $48 \mathrm{~h}$. For the recovery of adult female parasites, male SPF Wistar rats were deliberately infected with $S$. venezuelensis (2,000 larvae) during 15 days. Subsequently, rats were euthanasied (by concussion) and $15 \mathrm{~cm}$ of the intestines were removed, longitudinally sectioned, and placed in Petri dishes containing RPMI 1640 medium. The parasites leave the intestinal mucosa after 2 h of incubation at $37^{\circ} \mathrm{C}$. EEMz, HPFMz, LPFMz, F,$F_{3}$, and compounds 1 (chlorogenic acid) and $\mathbf{3}$ (myricitrin) were analysed. In order to increase the solubility in the culture medium, samples were dispersed in polyvinylpyrrolidone (PVP-K30) at 1:4 ratio. The assays were performed in 24-well plates containing RPMI 1640 medium (2 mL/well) supplemented with gentamicin $(50 \mathrm{mg} / \mathrm{L})$ and amphotericin $\mathrm{B}(2.5 \mathrm{mg} / \mathrm{L})$. Two parasites were transferred to each well and the plates were incubated under $5 \% \mathrm{CO}_{2}$ at $37^{\circ} \mathrm{C}$ for $72 \mathrm{~h} .50,100,200$ and $400 \mu \mathrm{g} / \mathrm{mL}$ were analysed. Positive control was treated under the same concentrations of ivermectin, while negative control only fresh medium containing PVP was used. At 6, 24, 48, and $72 \mathrm{~h}$, the motility and survival of the worms were evalueted and morphological changes was observed by DM500 microscope (Leica, Wetzlar, Germany). All the tests were performed in triplicate and survival curves were plotted using Prism 5.0 software (GraphPad, San Diego, CA, USA).

\subsection{Statistical analyses}

292 All analyses were performed in triplicate. Statistical significance was determined by the 293 Mantel-Cox test, using GraphPad Prism 5.0 software. The differences between the survival curves were considered statistically significant when the p-value was smaller than 0.001 .

\section{RESULTS AND DISCUSSION}


Bioguided studies of the antibacterial, antifungal, and anthelmintic (against $S$. venezuelensis) activities of the extract, fractions, and isolated compounds obtained from the leaves of M. zapota was firstly developed in this work. EEMz was obtained with a yield of $10.71 \%$ while LPFMz and HPFMz showed yields of $54.16 \%$ and $38.13 \%$, respectively.

\subsection{Identification of compounds in the LPFMz fraction}

GC-MS analyses revealed a predominance of pentacyclic triterpene compounds showing typical fragmentation patterns of ursane and oleane skeletons, with retention times between 40 and 47 minutes corresponding at 75\% of the all LPFMz fraction (Fig. 1). Table 1 shows the compounds identified from their fragmentation patterns, compared to data obtained from the NIST 11 library. The presence of long chain hydrocarbons and sterols in the aerial parts of M. zapota has been reported previously ${ }^{[21 ; 26]}$ and was confirmed here by the presence of compounds $\mathbf{A}, \mathbf{B}$, and $\mathbf{C}$. Please, insert here the Figure 1 and Table 1

313 Compound 5 presented a base peak at $m / z$ 204, accompanied by the ions with $m / z 189$

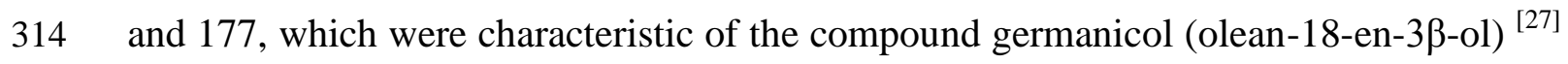
315 (Fig. 2). Peaks at $m / z$ 218, 203, and 189 were associated with retro-Diels-Alder type 316 fragmentation of ring $\mathrm{C}$ of olean-12-enes and ursan-12-enes. These characteristic peaks 317 were observed for compounds 6 and 7 identified as $\beta$ - and $\alpha$-amyrin, respectively. 318 Triterpene analogues of $\beta$-amyrin show greater abundance of the peak at $\mathrm{m} / \mathrm{z} 203$, compared to the peak at $m / z$ 189, while the $\alpha$-amyrin analogues show similar abundances of these peaks ${ }^{[27 ; 28]}$. The mass spectra of triterpene esters reflect the fragmentation pattern of the main skeleton, with smaller ions derived from the acid portion ${ }^{[29]}$. Hence, the fragmentation pattern of compound $\mathbf{8}$ corresponded to that expected for germanicol acetate $(\mathrm{m} / \mathrm{z}$ 468), with the fragments characteristic of germanicol (at $\mathrm{m} / z 204$ and 169), together with fragments at $\mathrm{m} / \mathrm{z} 453$ and 408 reflecting

325 the loss of methyl and acetyl groups, respectively, and a fragment at $\mathrm{m} / \mathrm{z} 43$ corresponding to $\mathrm{COCH}_{3}{ }^{[27]}$.

Please, insert here the Figure 2

328 Compounds 9 and $\mathbf{1 0}$ corresponded to $\alpha$ - and $\beta$-amyrin acetates, respectively, with 329 fragments peaks at $m / z, 218,203$, and 189 characteristics of amyrins and fragments with 
330 loss of the acetyl group ${ }^{[27]}$. Compound $\mathbf{1 1}$ was identified as lupeol acetate, with peaks at

$331 \mathrm{~m} / \mathrm{z} 453,408,365,218,189$, and $43^{[30]}$. Amyrins, amyrin acetates, and lupeol acetate

332 have been reported in leaves of $M$. zapota $^{[14 ; 16]}$. However, germanicol and its acetate

333 were firstly reported in the leaves of M. zapota in the current study. However, the

334 current study is the first time that germanicol and its acetate have been reported in $M$.

335 zapota leaves.

\subsection{Identification of compounds isolated from HPFMz}

338 Four compounds from HPFMz can be isolated and purified by preparative HPLC. 339 Compounds 1 (3.5 mg), 2 (0.7 mg), 3 (13.8 mg), and 4 (4.6 mg) showed retention times 340 of 2.01, 3.51, 4.14, and 5.26 min, respectively, detected in the HPLC analysis (Fig. 3).

341 The structures of the compounds were determined based on the one- and two342 dimensional NMR $\left({ }^{1} \mathrm{H},{ }^{13} \mathrm{C}, \mathrm{COSY}, \mathrm{HSQC}\right.$, and $\left.\mathrm{HMBC}\right)$, high-resolution mass 343 spectrometry, and optical rotation analyses.

\section{Please, insert here the Figure 3}

345 Compound 1 presented the molecular formula $\mathrm{C}_{16} \mathrm{H}_{18} \mathrm{O}_{9}$, with a mass of 354 . Its 346 structure was identified as that of chlorogenic acid (Fig. 4). The high-resolution 347 negative mode mass spectrometry analysis resulted in extraction of the $[\mathrm{M}-\mathrm{H}]^{-}$ion with $348 m / z$ 353.0872. The structural elucidation data corroborates Fayek et al. (2013) ${ }^{[19]}$, who 349 isolated this compound from the fruit of M. zapota. Other earlier studies have also been 350 identified chlorogenic acid in the fruit and seeds of M. zapota $^{[31 ; 32]}$. It could be inferred 351 from the ${ }^{1} \mathrm{H}$ NMR spectra of substances 2, 3, and 4 that they possessed similar base nuclei and belonged to the flavonoid class of compounds (Fig. 4). The pair of doublets at $\delta 6.18( \pm 0.8)(\mathrm{J}=2.0 \delta \pm 0.51 \mathrm{H})$ and $\delta 6.35( \pm 0.8)(\mathrm{J}=2.1 \pm 0.41 \mathrm{H})$ could be attributed to the 5,7,9,10-tetrasubstituted ring A, while the presence of two singlets at $\delta$ 6.95 ( \pm 0.8) was indicative of a flavonol with a $1^{\prime}, 3^{\prime}, 4^{\prime}, 5^{\prime}$-tetrasubstituted ring $\mathrm{B}$, corresponding to myricetin ${ }^{[33]}$.

\section{Please, insert here the Figure 4}

358 Considering the sugars linked to C-3 of the aglycones, compound 2 showed the presence of $\beta$-D-glucopyranoside unit, due to the high coupling constants $\left(J_{\mathrm{HH}}\right)$ involving each consecutive pair of $\mathrm{H}-1, \mathrm{H}-2, \mathrm{H}-3, \mathrm{H}-4$, and $\mathrm{H}-5$ protons of the sugar, varying between 8.8 and $11.9 \mathrm{~Hz}$, which is characteristic of protons in axial positions. 
362 For compounds 3 and $\mathbf{4}$, the same saccharide unit was attached to C-3. The signal at $\delta_{\mathrm{C}}$ $36317.6 \pm 0.2$, assigned to the C-6 methyl carbon of the sugar, together with the set of

364

365

366

367

368

369

370

371

372

373

374

375

376

377

378

379

380

381

382

383

384

385

386

387

388

389

390

391

392

393 signals at $\delta_{\mathrm{C}} 71.8( \pm 0.2), 72.1( \pm 0.4), 73.3( \pm 0.1)$, and $72.0( \pm 0.2)$, enabled its classification as a rhamnose.

HRESITOFMS spectrum of compound 2 presented pseudomolecular ion peaks [M + $\mathrm{H}]^{+}$with $m / z 481.0986$ (calculated for $\mathrm{C}_{21} \mathrm{H}_{21} \mathrm{O}_{13}$, with $m / z$ 481.0982) and $[\mathrm{M}-\mathrm{H}]^{-}$with $m / z 479.0820$ (calculated for $\mathrm{C}_{21} \mathrm{H}_{19} \mathrm{O}_{13}$, with $\mathrm{m} / \mathrm{z}$ 479.0826), giving the molecular formula $\mathrm{C}_{21} \mathrm{H}_{19} \mathrm{O}_{13}$ with mass of 480 . The structural elucidation of this compound was reported in other plants and identified as myricetin-3-O- $\beta-D-$ glucopyranoside ${ }^{[34 ; 35]}$. The absence of a smaller value of $J_{\mathrm{HH}}$ between the H-3" and H-4" protons confirmed that it was not a 3-O-galactoside ${ }^{[34]}$. The literature confirms the presence of myricetin-3-O- $\beta$ D-galactopyranoside in species of the Sapotaceae family ${ }^{[36]}$.

Compound 3 presented the molecular formula $\mathrm{C}_{21} \mathrm{H}_{19} \mathrm{O}_{13}$, with mass of 464 , derived of the base formula $\mathrm{C}_{21} \mathrm{H}_{19} \mathrm{O}_{12}$ resulting from the negative mode adduct $[\mathrm{M}-\mathrm{H}]^{-}$with $\mathrm{m} / \mathrm{z}$ 463.0877 (calculated for $\mathrm{C}_{21} \mathrm{H}_{19} \mathrm{O}_{12}$, with $\mathrm{m} / z$ 463.0877) and the positive mode ion $[\mathrm{M}+$ $\mathrm{H}]^{+}$with $m / z 465.1032$ (calculated for $\mathrm{C}_{21} \mathrm{H}_{21} \mathrm{O}_{12}$, with $\mathrm{m} / z$ 465.1033). This compound was identified as myricetin-3-O- $\alpha$-L-rhamnopyranoside, also known as myricitrin. This compound has also been identified in previous studies using the leaves of M. zapota $^{\text {[21; }}$ 33; 37].

${ }^{1} \mathrm{H}$ NMR data for compound 4 showed a signal characteristic of a methoxyl ( $\left.\delta 3.88\right)$. The location of this group was determined from the HMBC data, which showed its correlation with C-4' $(\delta$ 139.2) and with the two protons H-2' and H-6' responsible for the singlet at $6.87 \mathrm{ppm}$ of the aglycone. Using the ions $[\mathrm{M}-\mathrm{H}]^{-}$with $\mathrm{m} / \mathrm{z} 477.1039$ (calculated for $\mathrm{C}_{22} \mathrm{H}_{21} \mathrm{O}_{12}$, with $m / z$ 477.1033) and $[\mathrm{M}+\mathrm{H}]^{+}$with $m / z 479.1180$ (calculated for $\mathrm{C}_{22} \mathrm{H}_{23} \mathrm{O}_{12}$, with $\mathrm{m} / z$ 479.1190), it was possible to obtain the molecular formula of compound 4 as $\mathrm{C}_{22} \mathrm{H}_{22} \mathrm{O}_{12}$, with mass of 478 , identified as myricetin-3-O-4'methyl-ether-3-O- $\alpha$-L-rhamnopyranoside, also known as mearnsetin-3-O- $\alpha$-Lrhamnopyranoside (mearnsitrin). Take all results together, it is important to highlight that chlorogenic acid, myricetin-3-O- $\beta$-D-glucopyranoside, and mearnsitrin compounds in leaves of M. zapota were firstly detected in this work.

\subsection{In vitro antimicrobial activity}


MIC of the extracts, fractions, and isolated flavonoids of M. zapota are shown in Table 2. These results showed that EEMz, HPFMz, LPFMz were potentially active against $C$. albicans $(\mathrm{MIC}=16 \mu \mathrm{g} / \mathrm{mL}$ ). In the case of T. rubrum, EEMz and HPFMz presented moderate activity, while LPFMz was ineffective. HPFMz showed high activity against S. aureus and moderate activity against the other microorganisms. About the flavonoid, compound 2 showed significant activity against $S$. aureus $(\mathrm{MIC}=8 \mu \mathrm{g} / \mathrm{mL}$ ) and promising activity against T. rubrum $(\mathrm{MIC}=16 \mu \mathrm{g} / \mathrm{mL}$ ). Myricitrin (compound 3) presented promising activity against the gram-positive bacterium and the dermatophyte (MIC values of 32 and $64 \mu \mathrm{g} / \mathrm{mL}$, respectively). Mearnsitrin (compound 4) presented activity against $S$. aureus ( $\mathrm{MIC}=32 \mu \mathrm{g} / \mathrm{mL}$ ) and was ineffective against the other microorganisms.

\section{Please, insert here the Table 2}

It has been found that the presence of terpenoids and glycosidic flavonoids in crude extracts plays an important role in determining their antimicrobial activity ${ }^{[38]}$. The presence of such compounds in the extract and the higher polarity fraction could provide an explanation for the observed antimicrobial action against the pathogens tested. The results obtained to $C$. albicans corroborate previous studies using aqueous extract of leaves collected in India ${ }^{[39]}$ and various Candida species ${ }^{[40]}$. The antimicrobial properties of $M$. zapota extracts against $S$. aureus have been observed previously ${ }^{[39 ; 41]}$. These activities may be related to the isomeric mixture of $\alpha$ - and $\beta$ amyrin detected in the LPFMz that possesses known antimicrobial activity ${ }^{[42]}$. The presence of one or more sugar units at different positions of the aglycone can increase solubility and enhance the inherent medicinal properties of flavonoid compounds ${ }^{[43]}$. Taken together, all the samples originated from the leaves of M. zapota presented antimicrobial activities (of different magnitudes). These findings demonstrate the high antimicrobial potential of the leaves of $M$. zapota in combating three important human pathogenic microorganisms.

\subsection{In vitro anthelmintic activity assays}

423 The anthelmintic effect of EEMz, HPFMz, LPFMz, F,$F_{3}$, and isolated flavonoids (compounds 1 and 3) were evaluated by the survival percentage and cuticular integrity of female (L4) S. venezuelensis parasites. The positive control (with addition of PVP) 
presented $100 \%$ survival of the parasites. All samples tested at $400 \mu \mathrm{g} / \mathrm{mL}$ were lethal after $24 \mathrm{~h}$ to the parasites (Fig. 5). For EEMz, no survival of parasites at $72 \mathrm{~h}$ was observed to 100 and $200 \mu \mathrm{g} / \mathrm{mL}$ (Fig. 5A). HPFMz was lethal at $200 \mu \mathrm{g} / \mathrm{mL}$ after $48 \mathrm{~h}$, although survival at $72 \mathrm{~h}$ have been occurred for 100 and $50 \mu \mathrm{g} / \mathrm{mL}$ corresponding at $5.5 \%$ and $72 \%$, respectively (Fig. 5B). $\mathrm{F}_{2}$ was lethal at all concentrations tested after 72 $\mathrm{h}$ of incubation (Fig. 5C), while $\mathrm{F}_{3}$ was only lethal at the two highest concentrations (Fig. 5D). The parasites exposed to chlorogenic acid at $200 \mu \mathrm{g} / \mathrm{mL}$ died within the first $24 \mathrm{~h}$, while after $72 \mathrm{~h}$ there was no survival at any concentration (Fig. 5E). At $72 \mathrm{~h}$, there was no survival of the parasites exposed to myricitrin (compound 3) at 400 and $200 \mu \mathrm{g} / \mathrm{mL}$. However, the survive of the 11.1 and $61.1 \%$ were determined to 100 and 50 $\mu \mathrm{g} / \mathrm{mL}$, respectively (Fig 5F). It was possible to observe that all treatment had statistically significant difference of the control $(p<0.0001)$.

\section{Please, insert here the Figure 5}

Ivermectin (pharmacological control) reduced the motility of the organisms, but there was survival of all the individuals after $72 \mathrm{~h}$. Similar behavior to infective larvae (L3) of S. stercoralis using $250 \mu \mathrm{g} / \mathrm{mL}$ of ivermectin has been observed with reduction of the parasite motility and survive during 6 days ${ }^{[44]}$. The lower polarity fractions were also tested (data not shown) but showed unsatisfactory and imprecise results at all concentrations evaluated due the formation of insoluble clusters in the culture medium. At $100 \mu \mathrm{g} / \mathrm{mL}$, chlorogenic acid was lethal in the first $24 \mathrm{~h}$, while EEMz and $\mathrm{F}_{2}$ caused total mortality at the end of the incubation time (Fig. 6). At $200 \mu \mathrm{g} / \mathrm{mL}$, only chlorogenic acid was lethal after $24 \mathrm{~h}$. However, there was no survival for any of the samples tested after $72 \mathrm{~h}$. Images of the parasites after $72 \mathrm{~h}$ of incubation are shown in

449 Fig. 7. Parasites exposed to myricitrin (Fig. 7B) exhibited distortions and cuticular wrinkling. Those treated with F2 (Fig. 7C) showed distortions, depressions, and alterations in cuticular integrity, suggestive of direct cytotoxic effects on the morphology of the worms. The parasites exposed to ivermectin (Fig. 7D) exhibited

453 reduced motility, but the integrity of the cuticular surface remained similar to that of the positive control (Fig. 7A).

456 Thus, the first study describing the direct action of extracts, fractions, and isolated compounds obtained from $M$. zapota leaves on adult females of $S$. venezuelensis have 
been presented in this work, highlighting the potential anthelmintic activities, especially of the ethanolic extract, $\mathrm{F}_{2}$, and chlorogenic acid. The chemical analyses showed that both the ethanolic extract and the fractions contained glycosidic flavonoids as well as phenolic acids and their derivatives, suggesting that the effective anthelmintic action against the nematode was due to the presence of these compounds in the leaves of $M$. zapota.

Various studies of plant species have been undertaken in the search for new treatments for veterinary and human parasitosis. Free-living females of Strongyloides ssp. exposed to a methanolic extract of Lawsonia inermis have been analyzed taking into account the presence of distortions, and longitudinal and transverse cracks ${ }^{[45]}$. Sarojini et al. $(2012)^{[46]}$ reported strong anthelmintic action of L. inermis extract due to the presence of glycosides, terpenoids, and flavonoids. Carvalho et al. (2012) ${ }^{[47]}$ described the action of extracts of Piper tuberculatum, Lippia sidoides, and Mentha piperita against Haemonchus contortus

Ndhlala et al. (2016) ${ }^{[48]}$ described the chemical composition and anthelmintic activity of extracts of Achyranthes aspera against the free-living nematode Caenorhabditis elegans. The aqueous and acetone extracts of A. aspera exhibited strong activity, with UHPLC-MS/MS analyses revealing the presence of rutin, chlorogenic acid, and genistein, which were associated with the activity.

Comparison of the analogous flavonoids revealed a close relationship between their structures and antiparasitic activity. The presence of substituents (hydroxyl, methyl, methoxy, and glycosides) is fundamental to determine its effectiveness. In the case of hydroxyls, the number and pattern of hydroxylations in ring $\mathrm{B}$ has been found to have a major influence on the antiparasitic activity of flavonoids ${ }^{[49]}$. However, the mechanisms of action of flavonoids in helminths remain to be fully elucidated, even if several possibilities have been proposed: an increase in the supply of nitric oxide acting as a neurotransmitter in neuromuscular junctions and causing myoinhibition; nonspecific inhibition of esterases and cholinesterases leading to neuromuscular disorganization of the parasites; increased efflux of calcium causing depolymerization of the microtrabecular network, with consequent disorganization and disaggregation of the myofilaments; and decreased levels of free amino acids and increased levels of glutamic 
acid, glutamine, citrulline, and gamma-aminobutyric acid (GABA), leading to the release of nitric acid and resulting in neurological alterations ${ }^{[49]}$.

\section{CONCLUSIONS}

Antimicrobial, antifungal, and anthelmintic activities of the extract, fractions, and isolated compounds obtained from the leaves of Manilkara zapota were firstly evaluated. Another innovative find of this work was the identification of the compounds 1 (chlorogenic acid), 2 (myricetin-3-O- $\beta$-D-glucopyranoside), 4 (mearnsitrin), 5 (germanicol), and 8 (germanicol acetate) in M. zapota leaves. Ethanolic extract and fractions showed high antifungal activity against $C$. albicans. Compounds $\mathbf{3}$ (myricetin3-O- $\alpha$-L-rhamnopyranoside) and $\mathbf{4}$ presented promising activity against $S$. aureus while the high polarity fraction and compound $\mathbf{2}$ exhibited high activity against $S$. aureus and T. rubrum. The ethanolic extract and $\mathrm{F}_{2}$ containing phenolic compounds, and chlorogenic acid showed effective antiparasitic action against female (L4) $S$. venezuelensis parasites. This study contributes to the scientific basis for the possibility of using plants and compounds of natural origin to combat strongyloidiasis and microbial infections. The development of new therapeutic agents from $M$. zapota leaves will require further in-depth studies, but nonetheless this plant material appears to offer an effective alternative for the treatment of these diseases that are widespread and difficult to control.

\section{ACKNOWLEDGMENTS}

This work was supported by CAPES (scholarship) and FAPESP (process 20013/053551). The authors thank Glyn Mara Figueira and Benício Pereira (Agrotechnology Division of the Multidisciplinary Center for Chemical, Biological, and Agricultural Research (CPQBA) for identification of the species and provision of the plant material used in this work, respectively. We thank the BIO2MAR platform (http://bio2mar.obsbanyuls.fr) for providing technical support and access to instrumentation.

\section{CONFLICTS OF INTEREST}

The authors declare that they have no conflicts of interest. 


\section{REFERENCES}

523 1. Nii-Trebi NI. Emerging and neglected infectious diseases: Insights, advances, and challenges. Biomed Res Int 2017: 1-15.

2. Ayukekbong JA et al. The threat of antimicrobial resistance in developing countries: causes and control strategies. Antimicrob Resist In 2017.

3. Snowden R et al. A comparison of the anti- staphylococcus aureus activity of extracts from commonly used medicinal Plants. J Altern Complement Med 2014; 5: 375382.

4. Salakshna $\mathrm{N}$ et al. A cohort study of risk factors, clinical presentations, and outcomes for dermatophyte, nondermatophyte, and mixed toenail infections. J Am Acad Dermatol 2018; 6: 1145-1146.

5. Zhan $\mathrm{P}$ et al. Phylogeny of dermatophytes with genomic character evaluation of clinically distinct Trichophyton rubrum and T-violaceum. Stud Mycol 2018; 89: 153-175.

6. Zida A et al. Anti-Candida albicans natural products, sources of new antifungal drugs: A review. J Mycol Med 2017; 1: 1-19.

7. Lustigman $\mathrm{S}$ et al. A research agenda for helminth diseases of humans: the problem of helminthiases. PLoS neglected tropical diseases 2012; 4: e1582.

8. Olsen A et al. Strongyloidiasis - the most neglected of the neglected tropical diseases? Trans R Soc Trop Med Hyg 2009; 10: 967-972.

9. Winnicki $\mathrm{W}$ et al. Prevalence of Strongyloides stercoralis infection and hyperinfection syndrome among renal allograft recipients in Central Europe. Sci Rep-Uk 2018.

10. Mackey TK et al. Emerging and reemerging neglected tropical diseases: A review of key characteristics, risk factors, and the policy and innovation environment. Clin Microbiol Rev 2014; 4: 949-979.

11. Rocha JA et al. Anthelmintic, antibacterial and cytotoxicity activity of imidazole alkaloids from Pilocarpus microphyllus leaves. Phytother Res 2017; 4: 624-630.

12. Quattrocchi U. Crc world dictionary of plant names: Common names, scientific names, eponyms, synonyms, and etymology, 4: Boca Raton, 2000. 
13. Ganguly A et al. Evaluation of antinociceptive and antidiarrhoeal properties of Manilkara zapota leaves in Swiss albino mice. Pharmaceutical biology 2016; 8: 1413-9.

14. Chanda SV, Nagani KV. Antioxidant capacity of Manilkara zapota L. leaves extracts evaluated by four in vitro methods. Nat Sci 2010; 10: 260-266.

15. Pientaweeratch $S$ et al. Antioxidant, anti-collagenase and anti-elastase activities of Phyllanthus emblica, Manilkara zapota and silymarin: an in vitro comparative study for anti-aging applications. Pharmaceutical biology 2016; 9: 1865-1872.

16. Jain PK et al. Evaluation of analgesic activity of Manilkara zapota (leaves). Eur J Exp Biol 2011; 1: 14-17.

17. Kaneria M, Chanda S. Evaluation of antioxidant and antimicrobial properties of Manilkara zapota L. (chiku) leaves by sequential soxhlet extraction method. Asian Pac J Trop Biomed 2012; 3: S1526-S1533.

18. Salunkhe A et al. Antimicrobial activity of Psidium guajava and Manilkara zapota against human pathogenic bacteria. Int J Pharm Sci Res 2018; 9: 3944-3948.

19. Fayek NM et al. New triterpenoid acyl derivatives and biological study of Manilkara zapota (L.) Van Royen fruits. Pharmacognosy research 2013; 2: 55-9.

20. Giovannini $\mathrm{P}$ et al. Medicinal plants used in the traditional management of diabetes and its sequelae in Central America: A review. J Ethnopharmacol 2016: 58-71.

21. Fayek NM et al. Chemical and biological study of Manilkara zapota (L.) Van Royen leaves (Sapotaceae) cultivated in Egypt. Pharmacognosy research 2012; 2: 8591.

22. Ahmed R et al. Saponins from the seeds of Achras sapota. Journal of Asian natural products research 2008; 1-2: 7-16.

23. Noor $\mathrm{S}$ et al. Phytochemical, antioxidant, antimicrobial, thrombolytic as well as cytotoxic studies on the stem bark of Manilkara zapota (sapotaceae). Asian J Chem 2014; 18: 6138-6142.

24. Clsi. Methods for dilution antimicrobial susceptibility tests for bacteria that grow aerobically. Wayne, PA: Clinical and Laboratory Standards Institute, 11 Ed., 2018. 
25. Clsi. Reference method for broth dilution antifungal susceptibility testing of filamentous fungi. Wayne, PA: Clinical and Laboratory Standards Institute, 3 Ed., 2017.

26. Misra $\mathrm{G}$ et al. Constituents of Mimusops manilkara leaves and saponins of Mimusops seed kernels. Phytochemistry 1969: 2255-2256.

27. Oyo-Ita OE et al. Occurrence and sources of triterpenoid methyl ethers and acetates in sediments of the cross-river system, southeast Nigeria. International journal of analytical chemistry 2010: 502076.

28. Zanon RB et al. Phytoconstituents isolated from dichloromethane fraction of Vernonia tweediana Baker leaves. Brazilian J Pharmacogn 2008; 2: 226-229.

29. Fingolo $\mathrm{CE}$ et al. Triterpene esters: Natural products from Dorstenia arifolia (Moraceae). Molecules 2013; 4: 4247-4256.

30. Naumoska K, Vovk I. Analysis of triterpenoids and phytosterols in vegetables by thin-layer chromatography coupled to tandem mass spectrometry. J Chromatogr A 2015: 229-238.

31. Wang HY et al. Profiles and alpha-amylase inhibition activity of proanthocyanidins in unripe Manilkara zapota (Chiku). J Agr Food Chem 2012; 12: 3098-3104.

32. Kanlayavattanakul M, Lourith N. Sapodilla seed coat as a multifunctional ingredient for cosmetic applications. Process Biochem 2011; 11: 2215-2218.

33. Shen CJ et al. Polar constituents from sageretia thea leaf characterized by HPLCSPE-NMR assisted approaches. J Chinese Chem Soc 2009: 1002-1009.

34. Castillo-Munoz $\mathrm{N}$ et al. Flavonol 3-O-glycosides series of Vitis vinifera $\mathrm{Cv}$. Petit Verdot red wine grapes. J Agr Food Chem 2009; 1: 209-19.

35. Scharbert $S$ et al. Identification of the astringent taste compounds in black tea infusions by combining instrumental analysis and human bioresponse. $\mathrm{J} \mathrm{Agr}$ Food Chem 2004; 11: 3498-508.

36. Baky $\mathrm{MH}$ et al. A review on phenolic compounds from family Sapotaceae. $J$ Pharmacogn Phytochem 2016; 2: 280-287.

37. Braca A et al. Chemical composition and antioxidant activity of phenolic compounds from wild and cultivated Sclerocarya birrea(Anacardiaceae) leaves. J Agr Food Chem 2003; 23: 6689-95. 
38. Cowan MM. Plant products as antimicrobial agents. Clin Microbiol Rev 1999; 4: 564-582.

39. Abu Osman M et al. Antimicrobial investigation on Manilkara zapota (1.) p. Royen. Int J Drug Dev Res 2011: 185-190.

40. Otari SV et al. Green phytosynthesis of silver nanoparticles using aqueous extract of Manilkara zapota (L.) seeds and its inhibitory action against Candida species. Mater Lett 2014: 367-369.

41. Kaneria $M$ et al. Determination of antibacterial and antioxidant potential of some medicinal plants from Saurashtra Region, India. Indian J Pharm Sci 2009; 4: 406-412.

42. Fernandes $\mathrm{CP}$ et al. Triterpene esters and biological activities from edible fruits of Manilkara subsericea (Mart.) Dubard, Sapotaceae. Biomed Res Int 2013: 280810.

43. Ren G et al. Synthesis of flavonol 3-O-glycoside by UGT78D1. Glycoconj J 2012; 5-6: 425-432.

44. Boonmars $\mathrm{T}$ et al. In vitro antiparasitic activity of extracts of Cardiospermum halicacabum against third-stage larvae of Strongyloides stercoralis. Parasitol Res 2005; 5: 417-419.

45. Ismail KA et al. Comparison between the effect of Lawsonia inermis and flubendazole on Strongyloides species using scanning electron microscopy. $J$ Parasit Dis 2016; 2: 415-422.

46. Sarojini $\mathrm{N}$ et al. Correlation between the phytochemical constituents and anthelmintic activity of Lawsonia inermis leaf extracts. Int J Res Ayurveda Pharm 2012; 4: 559-562.

47. Carvalho $\mathrm{CO}$ et al. The anthelmintic effect of plant extracts on Haemonchus contortus and Strongyloides venezuelensis. Veterinary parasitology 2012; 3-4: 260-8.

48. Ndhlala AR et al. Antimicrobial, anthelmintic activities and characterisation of functional phenolic acids of Achyranthes aspera linn.: A medicinal plant used for the treatment of wounds and ringworm in east africa. Front Pharmacol 2015; 1663-9812 (Print). 
49. Kerboeuf D et al. Flavonoids and related compounds in parasitic disease control. Mini Rev Med Chem 2008; 2: 116-128.

646 


\section{FIGURE LEGENDS}

648 Fig. 1- Expanded chromatogram profile of the LPFMz

649 Fig. 2- Compounds detected by GC-MS in the LPFMz

650 Fig. 3- HPLC elution of the compounds 1, 2, 3, and 4 in the HPFMz.

651 Fig. 4- Compounds isolated from HPFMz.

652 Fig. 5- Anthelmintic activity of $M$. zapota against $S$. venezuelensis after $72 \mathrm{~h}$ of 653 incubation. Percentage survival of parasites exposed to: EEMz (A), HPFMz (B), $F_{2}(C)$, $654 \quad F_{3}(D)$, chlorogenic acid (compound 1) (E), and myricitrin (compound 3) (F). Control $655(\bullet), 50 \mu \mathrm{g} / \mathrm{mL}(\boldsymbol{\bullet}), 100 \mu \mathrm{g} / \mathrm{mL}(\boldsymbol{\Delta}), 200 \mu \mathrm{g} / \mathrm{mL}(\boldsymbol{\nabla})$, and $400 \mu \mathrm{g} / \mathrm{mL}(\bullet)$.

656 Fig. 6- Comparison of the anthelmintic activities of the extract, fractions, and 657 compounds obtained from the leaves of M. zapota at $100 \mu \mathrm{g} / \mathrm{mL}$ (A) and $200 \mu \mathrm{g} / \mathrm{mL}$ 658 (B). Control (•), EEMz (घ), $\operatorname{HPFMz}(\boldsymbol{\Delta}), \mathrm{F}_{2}(\boldsymbol{\nabla}), \mathrm{F}_{3}(\diamond)$, chlorogenic acid (compound 659 1) (०), and myricitrin (compound 3) ( $\square$ ).

660 Fig. 7- Parthenogenetic females of $S$. venezuelensis after exposure to $400 \mu \mathrm{g} / \mathrm{mL}$ for 72 $661 \mathrm{~h}$ of incubation. Parasite of the control group with preserved cuticle (A); Parasite 662 exposed to myricitrin, with cuticular wrinkling (arrow) (B); Parasite exposed to $\mathrm{F}_{2}$, with 663 cuticular alterations (arrows) (C); Parasite treated with ivermectin, with preserved 664 cuticular integrity (D). 
666 Table 1: GC-MS analysis of the chemical composition of the LPFMz

\begin{tabular}{|c|c|c|c|c|c|}
\hline Type & $\begin{array}{c}\text { RT }^{\mathbf{a}} \\
\text { (mints) }\end{array}$ & Compound $^{b}$ & $\mathbf{m} / \mathbf{z}$ & $\begin{array}{c}\text { Molecular } \\
\text { formula }\end{array}$ & $\begin{array}{c}\text { Peak area } \\
(\%)\end{array}$ \\
\hline $\mathbf{A}$ & 32.76 & Squalene & 410 & $\mathrm{C}_{30} \mathrm{H}_{50}$ & 5.94 \\
\hline B & 36.61 & n-Hentriacontane & 436 & $\mathrm{C}_{31} \mathrm{H}_{64}$ & 2.83 \\
\hline C & 37.35 & $\alpha$-Tocopherol & 430 & $\mathrm{C}_{29} \mathrm{H}_{50} \mathrm{O}_{2}$ & 0.86 \\
\hline 5 & 41.69 & Germanicol & 426 & $\mathrm{C}_{30} \mathrm{H}_{50} \mathrm{O}$ & 14.79 \\
\hline 6 & 42.13 & $\beta$-Amyrin & 426 & $\mathrm{C}_{30} \mathrm{H}_{50} \mathrm{O}$ & 3.89 \\
\hline 7 & 43.46 & $\alpha$-Amyrin & 426 & $\mathrm{C}_{30} \mathrm{H}_{50} \mathrm{O}$ & 6.54 \\
\hline 8 & 44.54 & Germanicol acetate & 468 & $\mathrm{C}_{32} \mathrm{H}_{52} \mathrm{O}$ & 4.84 \\
\hline 9 & 45.15 & $\beta$-Amyrin acetate & 468 & $\mathrm{C}_{32} \mathrm{H}_{52} \mathrm{O}_{2}$ & 13.90 \\
\hline 10 & 45.59 & $\alpha$-Amyrin acetate & 468 & $\mathrm{C}_{32} \mathrm{H}_{52} \mathrm{O}_{2}$ & 3104 \\
\hline 11 & 46.60 & Lupeol acetate & 468 & $\mathrm{C}_{32} \mathrm{H}_{52} \mathrm{O}_{2}$ & דט. \\
\hline
\end{tabular}

$667{ }^{\mathrm{a}}$ Retention time (mints).

$668{ }^{\mathrm{b}}$ Compounds listed in order of elution from an HP-5MS capillary column. 
Table 2: Minimum inhibitory concentrations (MICs) of the EEMz, HPFMz, LPFMz, and isolated flavonoids (compounds 2, 3, and 4) obtained from the leaves of M. zapota.

\section{$\operatorname{MIC}(\mu \mathrm{g} / \mathrm{mL})$}

\begin{tabular}{|c|c|c|c|c|c|c|c|}
\hline Microrganism & EEMz & HPFMz & LPFMz & 2 & 3 & 4 & Control $^{*}$ \\
\hline C. albicans (ATCC 10231) & 16 & 16 & 16 & $>128$ & $>128$ & $>128$ & $8^{\mathrm{a}}$ \\
\hline T. rubrum (SNB-TR1) & 256 & 128 & $>512$ & 16 & 64 & 128 & $3.125 \times 10^{-3 a} \quad 2^{b}$ \\
\hline S. aureus (ATCC 29213) & 128 & 32 & 128 & 8 & 32 & 32 & $2^{c}$ \\
\hline
\end{tabular}

$671 \quad$ *Positive control; ${ }^{\text {a fluconazole; }}{ }^{\mathrm{b}}$ itraconazole; ${ }^{\mathrm{c}}$ oxacillin.

672

673

674 Figure 1 Expanded chromatogram profile of the LPFMz.

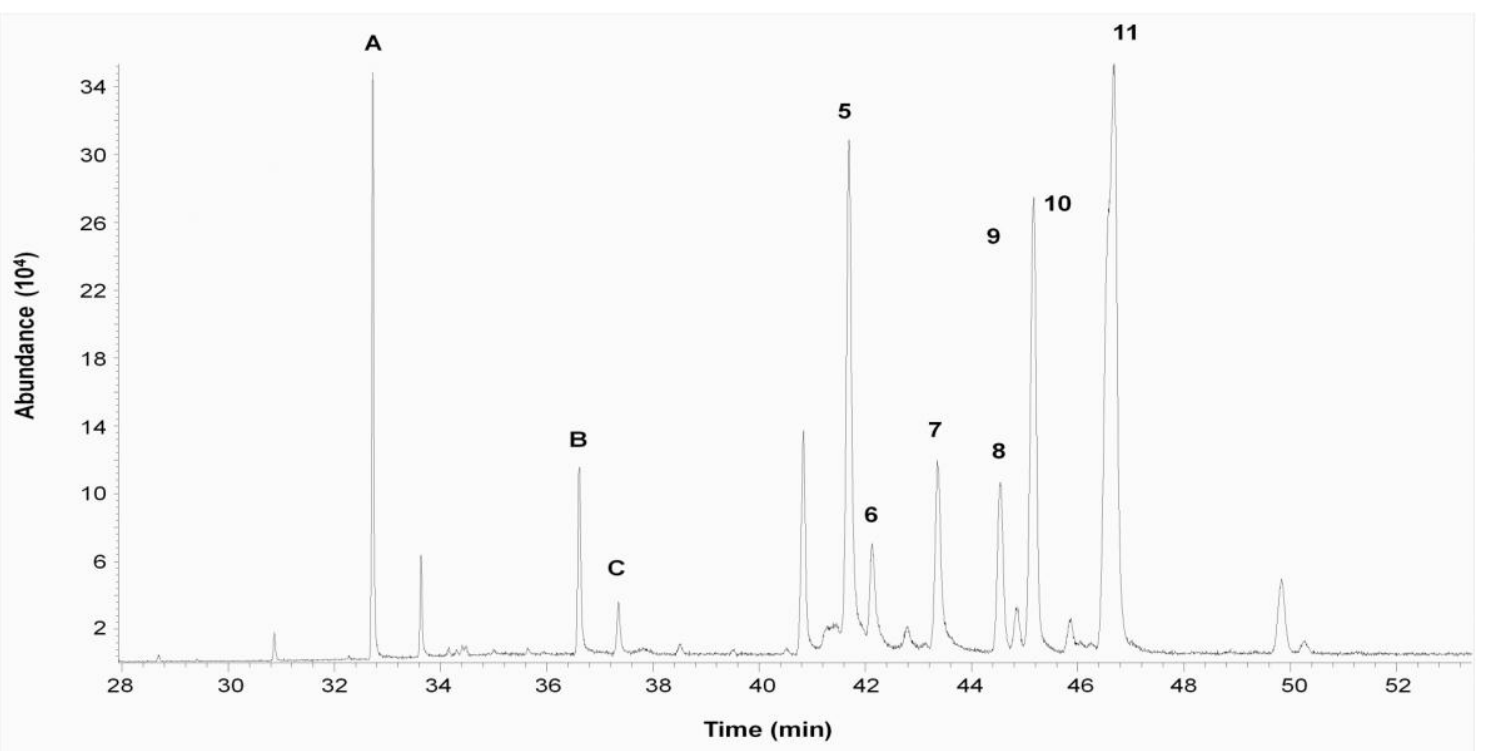

675

676

677 
Figure 2 Compounds detected by GC-MS in the LPFMz.
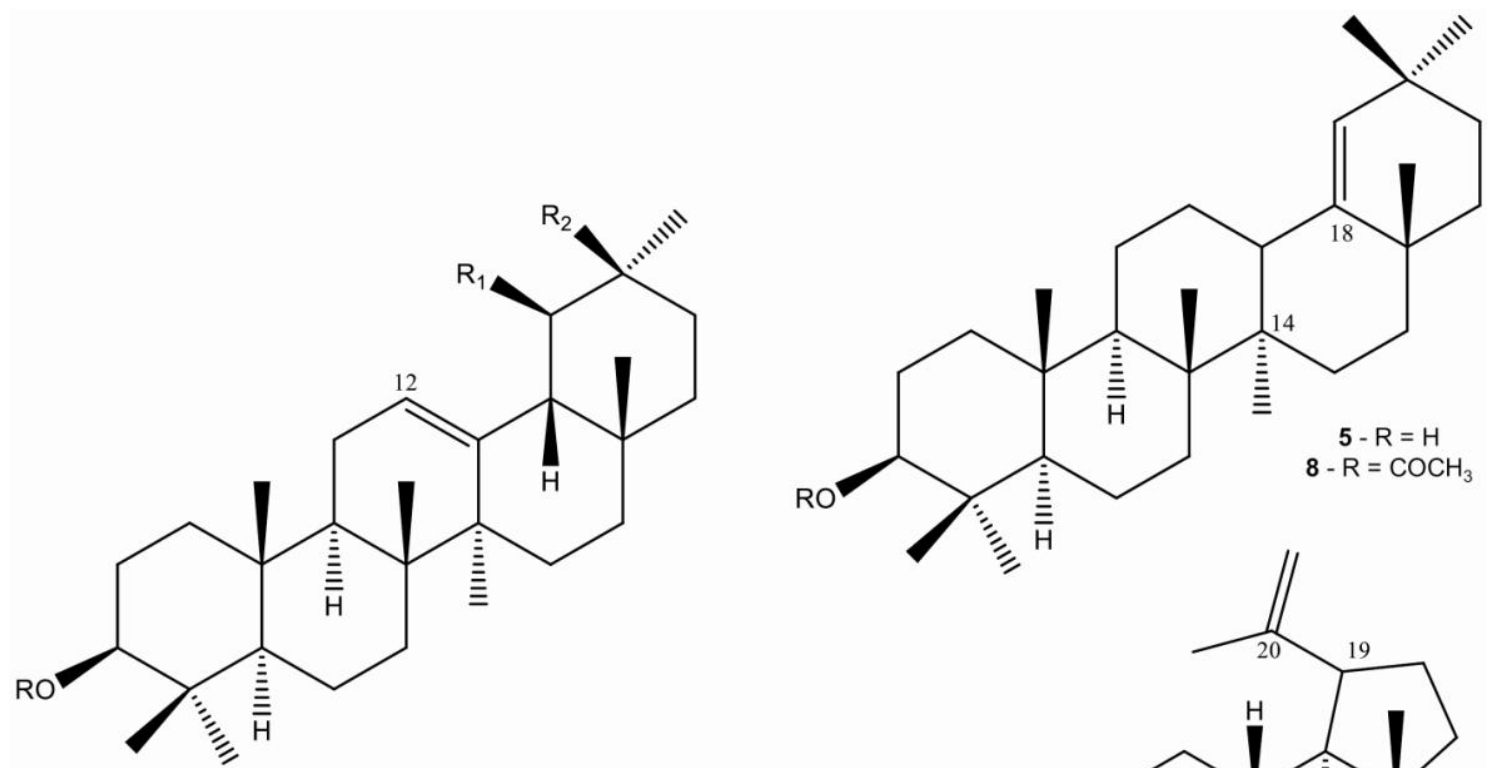

679

6 - $\beta$-amyrin - $\mathrm{R}=\mathrm{R}_{1}=\mathrm{H} ; \mathrm{R}_{2}=\mathrm{CH}_{3}$ 7 - a-amyrin $-\mathrm{R}=\mathrm{R}_{2}=\mathrm{H} ; \mathrm{R}_{1}=\mathrm{CH}_{3}$ 9 - $\beta$-amyrin acetate $-\mathrm{R}=\mathrm{COCH}_{3} ; \mathrm{R}_{1}=\mathrm{H} ; \mathrm{R}_{2}=\mathrm{CH}_{3}$ 10 - $\alpha$-amyrin acetate $-\mathrm{R}=\mathrm{COCH}_{3} ; \mathrm{R}_{2}=\mathrm{H} ; \mathrm{R}_{1}=\mathrm{CH}_{3}$

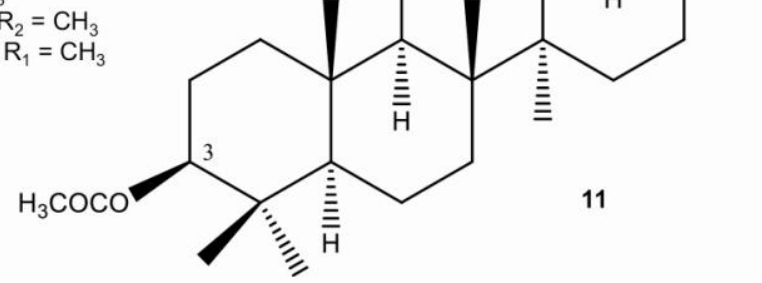

680

681 Figure 3 HPLC elution of the compounds 1, 2, 3 and 4 in the HPFMz.

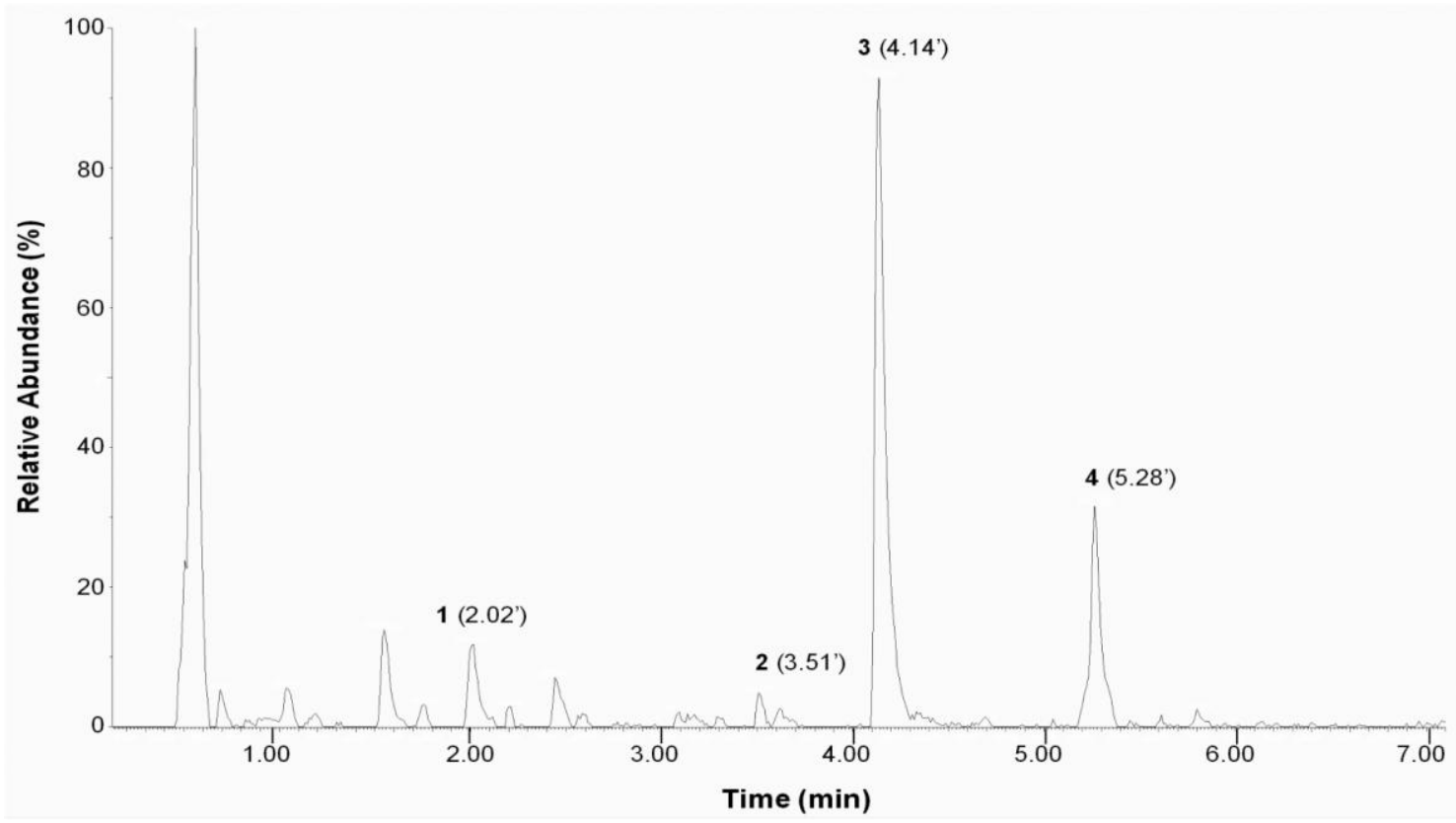


683 Figure 4 Compounds isolated from HPFMz.<smiles>O=C(/C=C\c1cccc(O)c1O)O[C@@H]1CC[C@@](O)(C(=O)O)[C@H](O)C[C@H]1O</smiles>

1: Chlorogenic acid<smiles>[R]Oc1c(-c2c[R](O)c([R2])c(O)c2)oc2cc(O)cc(O)c2c1=O</smiles>

2: $\mathrm{R}_{1}=\beta$ - D- glucopyranosyl; $\mathrm{R}_{2}=\mathrm{OH}$

3: $R_{1}=a-L$ - rhamnopyranosyl; $R_{2}=O H$

4: $\mathrm{R}_{1}=\mathrm{a}$ - L- rhamnopyranosyl; $\mathrm{R}_{2}=\mathrm{OCH}_{3}$

684

685

686 
687 Figure 5 Anthelmintic activity of M. zapota against S. venezuelensis after $72 \mathrm{~h}$ of 688 incubation. Percentage survival of parasites exposed to: EEMz (A), $\operatorname{HPFMz}(B), F_{2}(C)$, $689 \mathrm{~F}_{3}(\mathrm{D})$, chlorogenic acid (compound 1) (E) and myricitrin (compound 3) (F). Control $690(\bullet), 50 \mu \mathrm{g} / \mathrm{mL}(\boldsymbol{\bullet}), 100 \mu \mathrm{g} / \mathrm{mL}(\boldsymbol{\Delta}), 200 \mu \mathrm{g} / \mathrm{mL}(\boldsymbol{\nabla})$ and $400 \mu \mathrm{g} / \mathrm{mL}(\bullet)$.
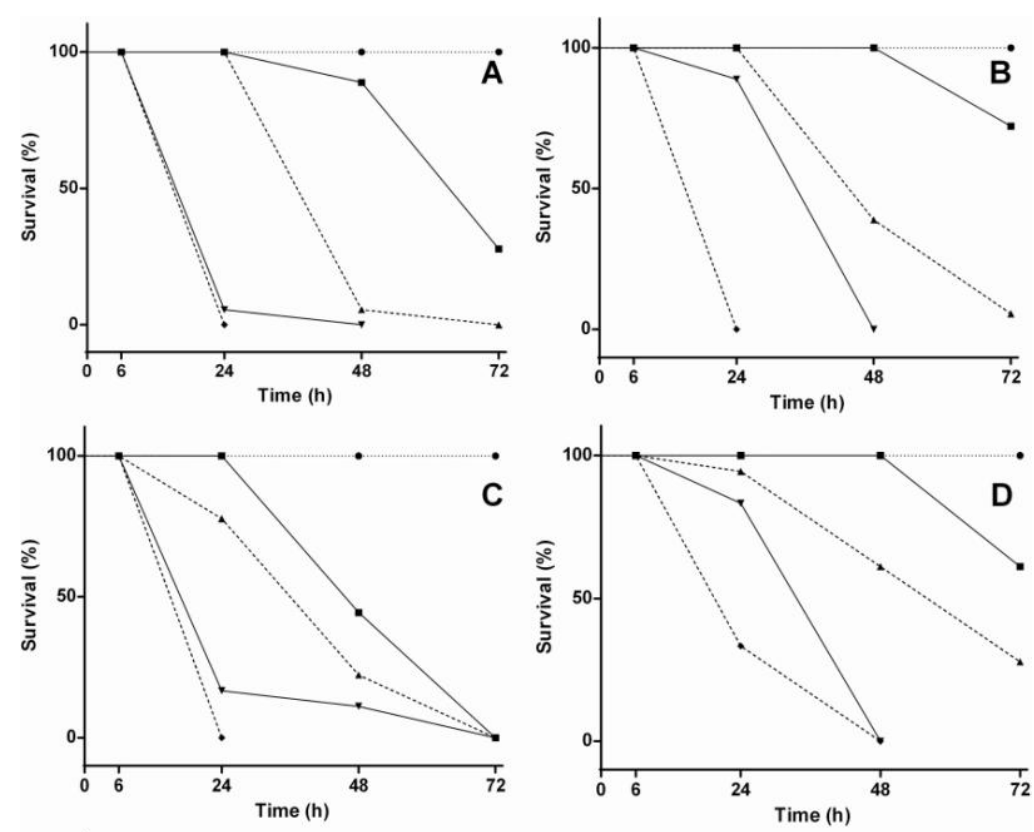

691
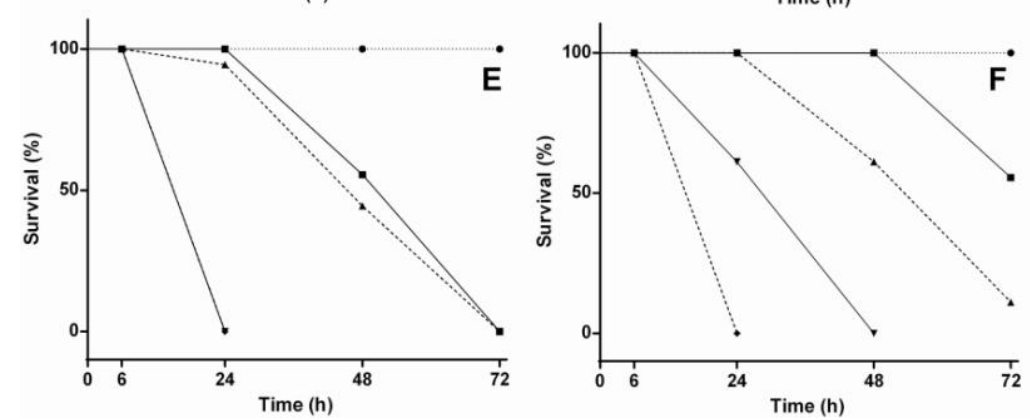

692

693 
694 Figure 6 Comparison of the anthelmintic activities of the extract, fractions, and 695 compounds obtained from the leaves of $M$. zapota at $100 \mu \mathrm{g} / \mathrm{mL}$ (A) and $200 \mu \mathrm{g} / \mathrm{mL}$

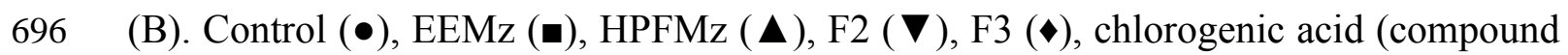
697 1) (०) and myricitrin (compound 3) ( $\square)$.

698
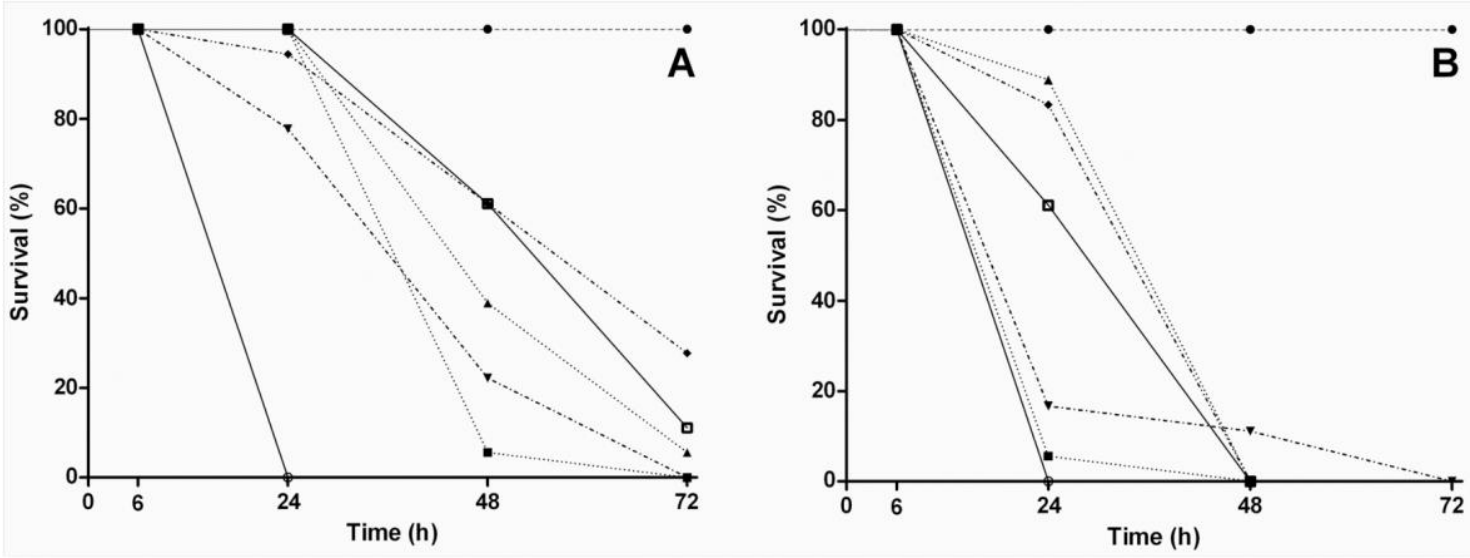

699 
701 Figure 7 Parthenogenetic females of S. venezuelensis after exposure to $400 \mu \mathrm{g} / \mathrm{mL}$ for $70272 \mathrm{~h}$ of incubation. Parasite of the control group with preserved cuticle (A); Parasite 703 exposed to myricitrin, with cuticular wrinkling (arrow) (B); Parasite exposed to F2, with 704 cuticular alterations (arrows) (C); Parasite treated with ivermectin, with preserved 705 cuticular integrity (D).

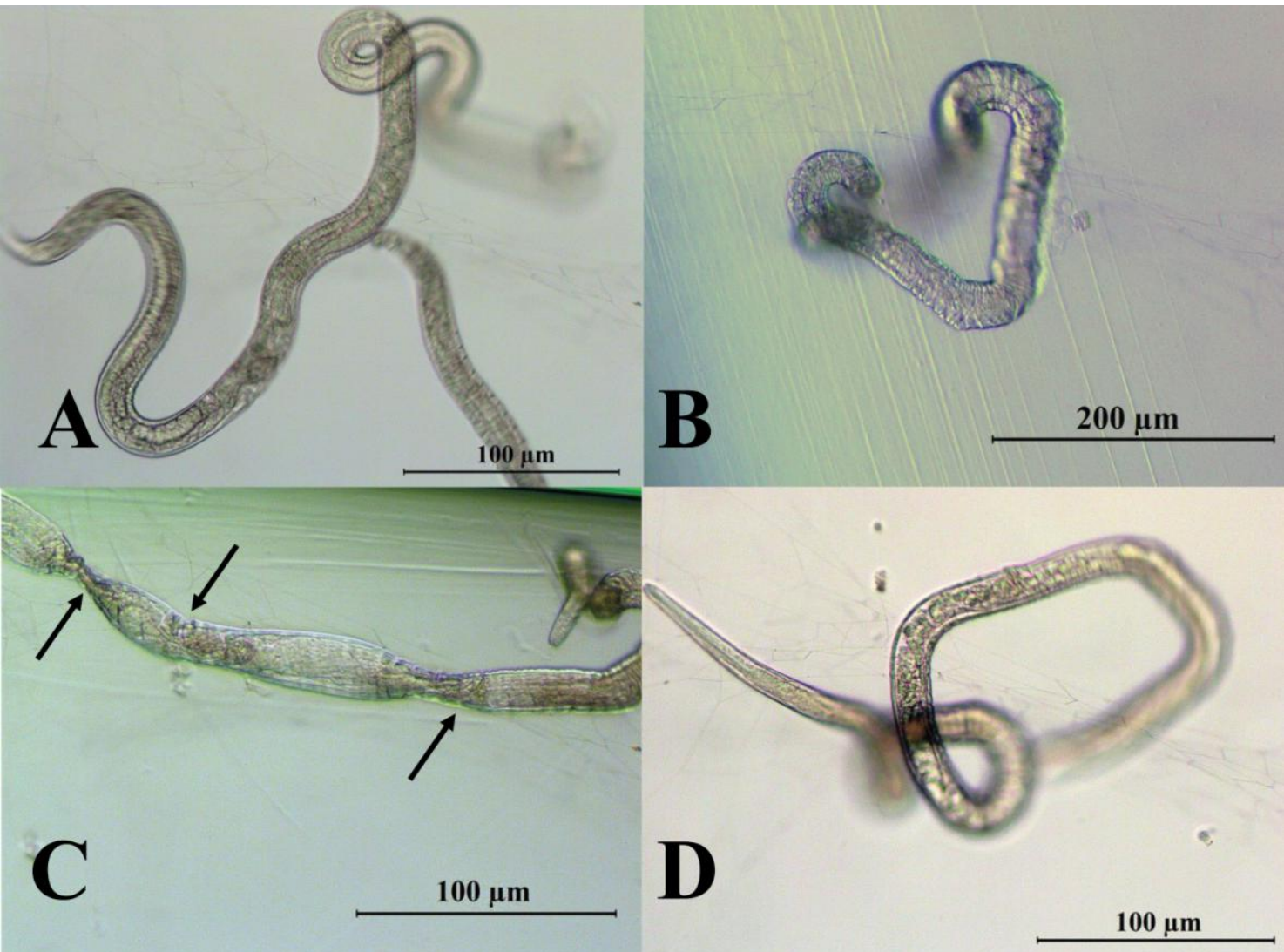

